\title{
PRESENT TRENDS IN PLANT TAXONOMY IN BANGLADESH AND ITS FUTURE
}

\author{
Haseeb Md. Irfanullah \\ School of Biological Sciences, Jones Building, University of Liverpool \\ Liverpool L69 $3 G S, U K$ \\ E-mail: hmirfan@liverpool.ac.uk,hmirfanullah@hotmail.com \\ Keywords: Plant taxonomy, plant systematics, Bangladesh
}

\begin{abstract}
The trend in plant taxonomic research in Bangladesh between 1972 and 2002 has been investigated by using a broad categorisation scheme and a scoring system. Inventory taxonomic studies (morphological taxonomic studies involving plant resources cataloging) were found to be significantly higher than the integrated studies (studies using the knowledge of different disciplines of biology). Studies on angiosperms were found to be significantly more than any other groups and followed by that on algae, while gymnosperms received significantly least attention. Despite the world-wide decline in taxonomic research, taxonomy can make significant contributions in Bangladesh if initiatives are taken to complete the inventory of plant resources through a country-wide campaign, to incorporate integrated approaches in traditional taxonomy and to stress on the conservation issues in taxonomic studies. Such efforts could be more effective if cooperation among institutions concerned with plant taxonomy could be increased through efficient networking.
\end{abstract}

\section{Introduction}

Taxonomy is a synthetic discipline (Stuessy 1990). It draws data from various branches of biology, namely, morphology, anatomy, embryology, paleobotany, palynology, cytology, genetics, cytogenetics, chemistry, reproductive biology and ecology. While traditional plant taxonomy is exclusively based on morphological features, in the last fifty years or so, by using the knowledge and techniques of other disciplines of biology, more integrated approaches are being taken to elucidate different issues of plant classification as well as phylogeny and evolution (e.g. Stuessy 1990). Taxonomy, specifically morphological taxonomy, however, is now experiencing an alarming decline (Disney 1998, Lee 2000). It is quite strong in the developed countries, where recent advancement in applied biology is attracting a large proportion of the research funds indicating commercialisation of biological research programmes. Despite the importance of all plant species in natural ecosystems, emphasis has now been given on specific plant species or plant groups because of their appealing economic benefits. 
On the contrary, in the less developed countries like Bangladesh the scenario is apparently less vigorous, but needs to be assessed. Recent comprehensive reviews on the studies carried out so far in Bangladesh on algae (Islam 1991a), bryophytes (Hadiuzzaman 1991), pteridophytes (Islam and Hadiuzzaman 1991), gymnosperms (Islam 1991b) and angiosperms (Khan 1991) have highlighted the importance of taxonomy in the overall plant studies in this country. During the British regime in the Indian subcontinent, plant taxonomy flourished as an essential part of the botanical exploration (Khan 1991). Although Bangladesh encompasses a small area compared to the whole subcontinent, the full inventory of her plant resources is yet to be completed. Regular reports on new taxa and new records of plants from different groups, especially angiosperms and·algae, suggest superb floristic richness and immense possibilities of taxonomic studies in this country.

The aim of this paper is to show the trends in plant taxonomic research in Bangladesh over the last three decades (1972-2002). A categorisation system and a scoring system are proposed to demonstrate the magnitude and the direction of such trends. Scopes and opportunities of plant taxonomic research in Bangladesh are also discussed.

\section{Approaches undertaken}

Three journals, publishing plant taxonomic research papers, namely, Bangladesh Journal of Botany (BJB by Bangladesh Botanical Society, 1972-2002), Journal of the Asiatic Society of Bangladesh, Science (JASBS by Asiatic Society of Bangladesh, 1975-June 2002) and Bangladesh Journal of Plant Taxonomy (BJPT by Bangladesh Association of Plant Taxonomists, 1994-2002) were consulted to identify, record and classify published plant taxonomic papers under a suggested categorysystem as described below. These three journals were selected because of their different magnitudes in publishing plant taxonomic papers: BJPT, exclusive for plant taxonomic papers; BJB, exclusive for botanical research papers including taxonomy and JASBS, all kinds of scientific papers including botanicals ones. All these journals are being published on a two-issue-per-year basis. Here algae, including blue-green algae (cyanobacteria), bryophytes, pteridophytes, gymnosperms and angiosperms were considered as plants. To be qualified as a study of Bangladesh the worked out material(s) (plant or place) must be from Bangladesh and should be carried out by one or more Bangladeshi scientists inside or outside Bangladesh. In addition, volumes of the Flora of Bangladesh (Khan et al. 1972-1996) were also included as revisions of angiospermic families. 


\section{Categories}

All the taxonomic research papers recorded were classified using two separate categorisation scheme. In the first scheme, all the papers were classified into two broad categories on the basis of the nature of the studies:

1. Inventory studies: This mostly includes area based floristic studies, checklists of certain areas or of certain taxonomic groups, new records of taxa, and revisions on genera, families and orders. Papers in relation to nomenclature like describing new taxa, proposing new combinations and changing names were mostly done in the papers of floristic studies. Micromorphological studies using light or electron microscopes and ethnobotanical studies with taxonomic perspective were also included in this category. The common feature of all these studies is traditional morphological taxonomic approaches (include both morphology and anatomy) were taken to carry out them.

2. Integrated studies: Studies, where knowledge of different branches of biology other than morphology, like chemistry, cytology, cytogenetics, ecology and reproductive biology were used with a definite aim to elucidate taxonomic problems or to facilitate taxonomic understanding were included in this category. Use of numerical methods in taxonomy was also incorporated in this group.

The second categorisation was done on the basis of the broad taxonomic group that a paper dealt with and the proposed six categories are:

1. Angiospermic studies: exclusively on angiospermic plants;

2. Gymnospermic studies: exclusively on gymnospermic species;

3. Pteridophytic studies: exclusively on fern and fern allies;

4. Bryophytic studies: exclusively on mosses and liverworts;

5. Algal studies: includes freshwater, brackish water and marine algal taxa; and

6. Mixed studies: any two or more of the above-mentioned categories.

\section{Scoring system}

A scoring system has been proposed to quantify the published works of a category in a given year. A paper scored three points, while a short communication scored one point. Each volume of the Flora of Bangladesh scored three points as a revision. Total score of a category in a given year was then used for statistical analyses. Nonparametric statistics, namely, Mann-Whitney tests and Spearman rank correlations were done to determine significant differences and correlations among the datasets, respectively. 


\section{Patterns revealed}

During the period of 1972-2002, the extent of inventory studies was significantly greater than that of integrated studies $(P<0.001)$ (Fig. 1). Moreover, a clear increase in the overall taxonomic studies was also evident since 1994. Inventory papers published in the studied journals were dominated by revisions, new records and floristic studies (Fig. 2A). Although cytogenetical studies were the major integrated studies, there was no significant difference among different integrated studies carried out (Fig. 2B) again suggesting very low attempt for such research. Figure 3 presents the overall trend of taxonomic studies in different plant groups. Studies on angiosperms were significantly higher than any other group, which was followed by algal studies, and gymnosperms received least attention. Correlations between different types of studies also showed similar magnitude in different plant groups (Table 1). Inventory studies as a whole showed strong positive correlation with most

Table 1. Results of Spearman rank correlations among different types of taxonomic studies and plant groups calculated on the basis of yearly scores. Different integrated studies were not included separately because of their very low individual yearly scores. Total, sum of inventory and integrated studies; + , positive correlation; $*$ negative correlation; ns, not significant at $P<0.05 ; * P<0.05 ; * * P<0.01 ; * * * P<0.001$.

\begin{tabular}{|c|c|c|c|c|c|c|c|c|c|c|c|c|c|c|c|}
\hline & Total & Inven. & Integ. & Alga. & Bryo. & Pteri. & Gym. & Angi. & Mix. & Nom. & Micro. & Rev. & Flor $N$ & New & Check \\
\hline Inventory & $\begin{array}{c}+ \\
* * * *\end{array}$ & & & & & & & & & & & & & & \\
\hline Integrated & $\stackrel{+}{* *}$ & $\begin{array}{l}+ \\
*\end{array}$ & & & & & & & & & & & & & \\
\hline Algae & $\stackrel{+}{+}$ & $\underset{* * * *}{+}$ & ns & & & & & & & & & & & & \\
\hline Bryo. & $\underset{* * *}{+}$ & $\underset{* * * *}{+}$ & $\mathrm{ns}$ & ns & & & & & & & & & & & \\
\hline Pterido. & $\underset{* * *}{+}$ & $\underset{* * * *}{+}$ & $\mathrm{ns}$ & $\stackrel{+}{+}$ & $\begin{array}{l}+ \\
*\end{array}$ & & & & & & & & & & \\
\hline Gymno. & ns & $\mathrm{ns}$ & ns & ns & ns & + & & & & & & & & & \\
\hline Angio. & $\stackrel{+}{+}$ & $\stackrel{+}{+}$ & $\underset{* *}{+}$ & $\stackrel{+}{+}$ & $\stackrel{+}{* *}$ & $\stackrel{+}{+}$ & ns & & & & & & & & \\
\hline Mixed & $\stackrel{+}{* *}$ & $\begin{array}{l}+ \\
* *\end{array}$ & ns & $\underset{* *}{+}$ & $\mathrm{ns}$ & ns & ns & $\stackrel{+}{*}$ & & & & & & & \\
\hline Nomen. & + & $\stackrel{+}{* *}$ & ns & + & $\begin{array}{l}+ \\
*\end{array}$ & + & ns & $\underset{* *}{+}$ & ns & & & & & & \\
\hline Micromor & $\begin{array}{l}+ \\
* *\end{array}$ & + & + & $\underset{* *}{+}$ & ns & ns & $\begin{array}{l}+ \\
*\end{array}$ & $\stackrel{+}{+}$ & $\underset{* *}{+}$ & $\begin{array}{l}+ \\
*\end{array}$ & & & & & \\
\hline Revision & $\mathrm{ns}$ & ns & ns & * & $\begin{array}{l}+ \\
*\end{array}$ & ns & ns & ns & ns & ns & $\bar{*}$ & & & & \\
\hline Floristic & $\underset{* * *}{+}$ & $\underset{* * *}{+}$ & ns & $\underset{* * *}{+}$ & ns & $\underset{* *}{+}$ & + & $\underset{* * *}{+}$ & $\stackrel{+}{+}$ & + & $\underset{* * *}{+}$ & $\bar{*}$ & & & \\
\hline New Rec. & $\stackrel{+}{+* *}$ & $\stackrel{+}{+}$ & ns & $\underset{* * *}{+}$ & $\stackrel{+}{+*}$ & $\underset{* * *}{+}$ & ns & $\underset{*: * * *}{+}$ & $\begin{array}{c}+ \\
* *\end{array}$ & $\stackrel{+}{*}$ & ns & ns & $\underset{* *}{+}$ & & \\
\hline Checklist & $\underset{* * *}{+}$ & $\underset{* * *}{+}$ & ns & $\underset{* * *}{+}$ & $\stackrel{+}{* * *}$ & $\underset{* * *}{+}$ & ns & $\stackrel{+}{+}$ & $\stackrel{+}{*}$ & + & ns & ns & $\begin{array}{l}+ \\
* * *\end{array}$ & $\stackrel{+}{+}$ & \\
\hline Ethnobot. & $\begin{array}{l}+ \\
* *\end{array}$ & $\begin{array}{l}+ \\
* *\end{array}$ & ns & ns & $\underset{* *}{+}$ & + & ns & $\stackrel{+}{*}$ & + & ns & ns & ns & ns & $\begin{array}{c}+ \\
* * *\end{array}$ & $\stackrel{+}{+}$ \\
\hline
\end{tabular}


of the plant groups, while combined integrated studies only showed correlation with angiospermic studies. Among different inventory studies, floristic, new records and checklists showed highest correlations with other types of work, whereas revisions showed the least. Publication of the Bangladesh Journal of Plant Taxonomy has enhanced an significant increase in the overall plant taxonomic research in Bangladesh compared to the yearly contributions made by the Bangladesh Journal of Botany and the Journal of the Asiatic Society of Bangladesh, Science in the earlier two decades (Fig. 1, Table 2).

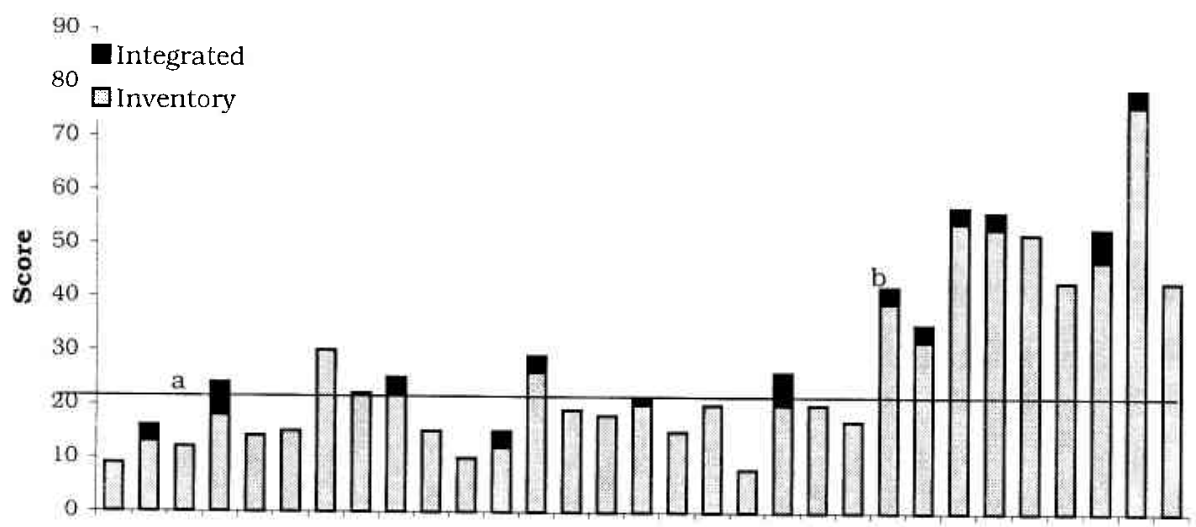

72737475767778798081828384858687888990919293949596979899000102 Year

Fig. 1. Yearly scores of inventory and integrated taxonomic studies over a period of 1972-2002. The horizontal line across the bars is the overall mean of the combined score per year. Letters ' $a$ ' and ' $b$ ' indicate the first publication of the Journal of the Asiatic Society of Bangladesh, Science and Bangladesh Journal of Plant Taxonomy, respectively.

\section{Global status of taxonomic studies}

A recent sharp decline in traditional taxonomic studies has been well recognised, which is quite evident in developed countries than in developing countries (Bramley 1994, Disney 1998, Lhotsky 1998, Lee 2000). Traditional morphological taxonomy is now facing two-way attack: one from its sister discipline molecular systematics (Lee 2000) and the other from the other applied disciplines of biology (Boero 2001). Funding for research in biological sciences is increasing, but is almost exclusively controlled by the commercial benefits of the funding agencies. Hence applied disciplines, like pharmacy, molecular biology and plant transformation are getting increasing attention rather than those dealing with basic sciences. Similarly, funds coming into systematics studies are mostly taken up by projects dealing with specific 
plant species with specific economic importance, leaving the traditional taxonomy with more or less empty hands. Moreover, now-a-days taxonomic studies are considered as an old-fashioned, non-creative research in the intellectual arena of biological sciences. Thus molecular biology and other applied science courses are getting preference in the universities and flourishing progressively, while taxonomy courses are dwindling (Lhotsky 1998, Boero 2001). Nonetheless, unequal cash flows into the different branches of biological sciences also controlling the career perspective of the young researchers. Journals publishing classical taxonomic papers have lower Impact Factors (Lee 2000, Valdecasas et al. 2000), thus are less appealing to the funding agencies and are also less useful in career building. Exclusive publication of experimental research articles in the new as well as in the established journals of plant biology and systematics also demonstrates this development (Lee 2000). All these are driving young researchers to take the 'advanced' avenues of biological sciences with better job prospects (Boero 2001).

\section{Plant taxonomy: Bangladesh scenario}

In a developing country like Bangladesh the picture is a bit different. In recent years, the funds for environmental projects have been increased considerably, and are available from both internal and external sources. These mostly provide support to the projects on sustainable development of rural communities or conservation of threatened ecosystems through community participations. Inventory and monitoring of plant species are often being carried out under these projects as a part of the documentation of the natural resources of the project areas. Despite the present political recognition of the importance of biodiversity, funding for basic research in the field of plant taxonomy is megre. In terms of plant taxonomic expertise, the Botany departments of the University of Dhaka, University of Chittagong, Jahangirnagar University and Rajshahi University, and institutes, such as, Bangladesh Council for Scientific and Industrial Research (BCSIR) of Chittagong, Bangladesh Forest Research Institute (BFRI) and Bangladesh National Herbarium (BNH) are the important bodies harbouring around 35 academics and scientists actively involved in plant taxonomic and ethnobotanical research. Among these the $\mathrm{BNH}$ can be considered as the icon of the plant taxonomic research in Bangladesh. In addition to the three mentioned journals, other journals that publish taxonomic articles are the University Studies of the above-mentioned universities and the bulletins of the BFRI. Moreover, different books have also documented the plants of different broad groups of Bangladesh, such as medicinal plants (Khan and Huq 1975), aquatic plants (Khan and Halim 1987), mangroves (Hussain and Acharya 1994), trees (Das and Alam 2001) and plants of different bio-ecological zones of Bangladesh (Nishat et al. 2002). 
Although the status of plant taxonomy in Bangladesh is not falling down, but not flourishing either in the way it should be considering the prevailing opportunities. The clear increase in plant taxonomic studies in Bangladesh in the last 10 years or so is the direct result of the regular publication of the Bangladesh Journal of Plant Taxonomy (Fig. 1, Table 2). While this suggests the importance of specialised journals for promoting the advancement of a scientific discipline, the overall picture of plant taxonomy in Bangladesh is not that satisfactory. In next few sections, I shall discuss the scopes and opportunities that can be explored for the enhancement of plant taxonomic research in Bangladesh.

Table 2. Overall mean scores of different types of taxonomic studies in Bangladesh related to three different periods characterised by journals. See the section Approaches undertaken for abbreviations. Different small letters in the same column represent values that are different at $\boldsymbol{P}<0.05$, values with asterisks (*) were not included in such comparison because of their very low values.

\begin{tabular}{|c|c|c|c|c|c|c|c|c|}
\hline \multirow[b]{2}{*}{ Journals } & \multicolumn{2}{|c|}{ Types of studies } & \multicolumn{6}{|c|}{ Major groups studied } \\
\hline & Invent. & Integra. & Algae & Bryo. & Pterido. & Gymno. & Angio. & Mixed \\
\hline $\begin{array}{l}\text { BJB } \\
(1972-1974)\end{array}$ & 9 a & $1 \mathrm{a}$ & $7 a b$ & $0^{*}$ & $0 *$ & $0 *$ & $3.3 \mathrm{a}$ & $0^{*}$ \\
\hline $\begin{array}{l}\text { BJB+JASBS } \\
(1975-1993)\end{array}$ & $11 \mathrm{a}$ & $1.2 \mathrm{a}$ & $3.6 \mathrm{a}$ & $0.6 \mathrm{a}$ & $0.2 \mathrm{a}$ & $0 *$ & $7.3 \mathrm{a}$ & $0.3 \mathrm{a}$ \\
\hline $\begin{array}{l}\text { BJB+JASBS+BJPT } \\
(1994-2002)\end{array}$ & $47 \mathrm{~b}$ & $2.3 \mathrm{a}$ & $12 b$ & $4.9 \mathrm{~b}$ & $3.6 \mathrm{~b}$ & $0.1 *$ & $27 \mathrm{~b}$ & $1.7 \mathrm{a}$ \\
\hline
\end{tabular}
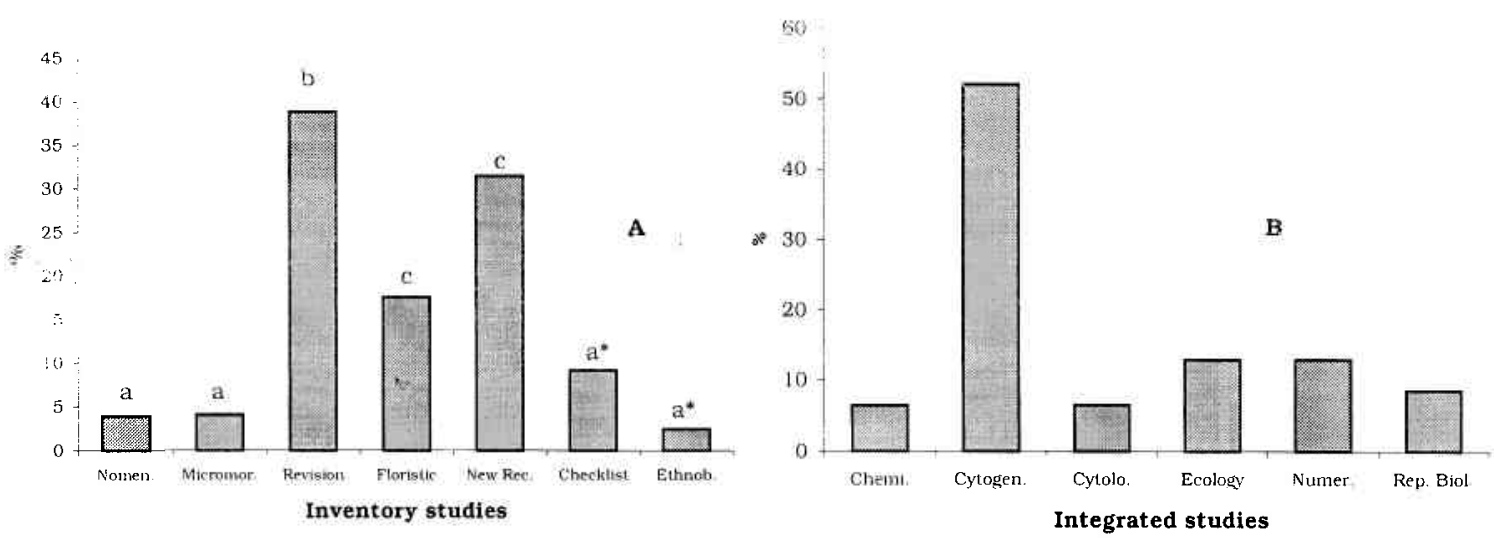

Fig. 2. Overall mean scores of different taxonomic studies as the percentages of total A) inventory or B) integrated studies. In graph A, bars with different small letters are different at $P<0.05$ as determined on the basis of yearly scores; bars with asterisks are significantly different from each other. Inventory studies include nomenclatural. micromorphological, revision, floristic, new records, checklists and ethnobotanical studies; and integrated studies include chemical, cylogenetical, cytological, ecological, numerical and reproductive biological studies. 


\section{Acceleration of inventorying and conservation initiatives}

The present study suggests that the strength of plant taxonomy in Bangladesh is in inventory taxonomy (Fig. 1, Table 1). However, despite the long tradition of such taxonomic research in Bangladesh (Khan 1991), we are yet to finish our complete inventory of plant resources. Still many areas, especially in the Chittagong Hill Tracts, remain floristically unexplored. Sporadic collections and floristic studies are continuously contributing to the species list of Bangladesh (Fig. 2A), although the low proportion of nomenclatural studies undermines the actual extent of these studies as most of the reports on new to science taxa are published in revision or floristic papers. However, with the current rate of documentation, it seems to be a long way to have a complete list of the flora of Bangladesh. An encouraging initiative was taken by the Bangladesh National Herbarium with the financial support from the government in the mid-1990s for a comprehensive inventory of the plant resources of the country, from algae to angiosperms. But unfortunately it was not executed due to some unresolved problems. Completion of such large-scale inventory is very essential, importance of which has literary been over-emphasised on different occasions.

To accelerate the taxonomic exploration in Bangladesh, botany teachers of colleges or equivalent academic institutions with B.Sc. and M.Sc. degrees could be encouraged in undertaking taxonomic inventories. A detailed plan for that could be designed involving leading taxonomic experts of the country, and concerned bodies and officials of education and environment ministries of the government, and accordingly those teachers could be trained to carry out such country-wide project. At present regular training programmes are organised for the college teachers every year by the government as a part of the skill enhancement programme. The proposed 'training programme on taxonomy' can be tied up with the existing training scheme. Moreover, botanists involved in different environmental projects can also be included in similar training programmes. Such use of non-specialist taxonomists to expedite inventory by sieving out well-recognised taxa and by leaving rare, difficult or new ones for experts' consideration is well discussed (Alberch 1993, Beattie and Oliver 1994. Brower 1995). Such an endeavour will in fact trigger a country-wide movement of taxonomic exploration, which is urgently needed, and the findings will facilitate the publication of the complete flora of Bangladesh including all plant groups. However, we should be careful that this passion of recording species does not compromise with the rigidity and reliability of taxonomy as science (Renner and Ricklefs 1994). Moreover, we should be cautious enough in designing such programme to avoid the fate of such initiative taken by the INBio (Instituto Nacional de Biodiversidad) of Costa Rica in terms of insufficient training, erroneous sampling, slow identification, poor performance of para-taxonomists leading towards disappointing outputs (Lobo 1994). 
Besides complete inventory, another prime issue, which I think the future of taxonomic studies in Bangladesh lies with, is the conservation of plant diversity. At present our activity is limited to mere survey of the conserved areas. Although it is the first step to start with, but is not the main focus of conservation. Continuous monitoring, an essential part of the whole conservation scheme (Yoccoz et al. 2001), is almost absent in the present conservation programmes. Furthermore, like anywhere in the world, threatened plants of Bangladesh have received less attention compared to the threatened animals. However, the recent publication of the Red Data Book of Vascular Plants of Bangladesh (Khan et al. 2001) can be a very important tool to guide the plant conservation movement in Bangladesh. In this volume, a total of 106 plant species are listed as threatened after an extensive literature survey, search in herbaria and accompanying field works. Still, listing of 99 species as either 'Data Deficient' or 'Not Evaluated' indicates the need for more intensive investigation in this regard. Nonetheless, ecosystem approaches would always be more preferable in any conservation initiatives, especially when lower plant groups are involved.

\section{Vitalization of integrated approaches}

The second important issue identified by the present study is the lack of integrated approaches in taxonomic studies (Fig. 1, 2B, Table 1). But there are excellent scopes for undertaking collaborative studies involving cytology (e.g. Begum et al. 1994), cytogenetics (e.g. Sobhan et al. 1991, Alam et al. 2000), biochemistry (e.g. Alam et al. 2000), breeding and life-cycle for elucidating taxonomic issues, like delimiting taxa, or those involving ecology, reproductive biology and tissue culture for the conservation of threatened species. Lack of advanced technologies or funding cannot be an excuse for staying away from such initiatives. If necessary, we need to modify the available techniques and continue studies with our available resources, while looking for other routes for further advancement. Integrated studies in collaboration with workers from other branches of botany/biology will be more effective than sole efforts by the taxonomists. Such alliance will definitely improve our outlook towards taxonomy, thus it is the taxonomist who should initiate such venture. We should learn from the USA, which once neglected its traditional taxonomy, has now started the Partnership for Enhancing Expertise in Taxonomy (PEET) programme, a combination of morphological taxonomy and molecular systematics to get maximum out of taxonomy (Boero 2001).

\section{Balance in studies of different plant groups}

In the taxonomic studies in Bangladesh there are comparatively less emphases on the plant groups other than angiosperms (Fig. 3, Table 1). Although the Bangladesh National Herbarium (BNH) is the sole institute exclusive for plant systematics, even it does not include lower plant groups in its regular activities. 
Despite their importance in nature, inconspicuous, microscopic organisms are less appealing to common people and also to the research funders. But they should not be to the trained botanists. In case of algae, although there is a huge scope and need for phyco-limnological studies in Bangladesh, we only have a couple of active phycologists, and phycological studies are almost based at the University of Dhaka and the Rajshahi University. Moreover, there is virtually no integrated study on the lower plant groups, namely, algae and bryophytes. This scenario should be altered by changing the perspectives of concerned workers and by undertaking systematic studies incorporating life-history studies, and cytological, cytogenetical and biochemical approaches. The BNH should also come forward with specific projects on lower plant groups and should include phycologists and bryologists in its working team. In the other two least studied groups, pteridophytes and gymnosperms, focus should be given on their conservation as they bear significant number of endangered species (Khan et al. 2001).

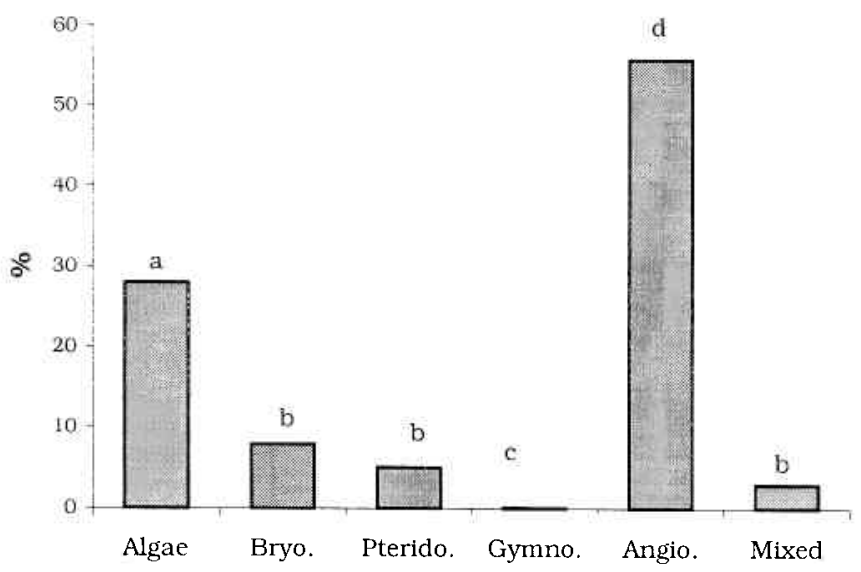

Taxonomic group

Fig. 3. Overall mean scores of different plant groups as the percentages of total score; bars with different small letters are different at $P<0.05$.

\section{Enhancement of institutional collaboration}

For the advancement of plant taxonomic research, cooperation among the organisations involved in plant taxonomic studies is very important. In this regard, the Bangladesh National Herbarium (BNH) and the Bangladesh Association of Plant Taxonomists (BAPT), two platforms of plant taxonomic research and conservation of plant resources in Bangladesh, can effectively work together and they have already demonstrated the fruitfulness of their collaboration in the last ten years or so. One of 
the important activities of the BAPT is the publication of the Bangladesh Journal of Plant Taxonomy (BJPT), regular publication of which has undoubtedly accelerated the pace of taxonomic research in Bangladesh (Table 2). But strong effort should be made to publish BJPT regularly, and to publish its abstracts in international abstracting journals and also on abstracting databases available on internet to improve its international acceptability.

As an expansion of their collaboration, BNH and BAPT should also take the initiatives to bring together organisations, like Botany departments, institutes, different botanical associations like Bangladesh Botanical Society and groups involved in commercial use of plants, both from the country and abroad, to establish a network of all possible stakeholders to facilitate a movement in integrated taxonomic studies in Bangladesh. Besides, such networking can also help in developing an electronic database on the flora of Bangladesh, and contribute to the improvement of the libraries, herbaria and research facilities for plant taxonomy.

\section{Conclusion}

Through the above discussion one thing I was trying to illuminate is that taxonomy needs a change in the attitude of the taxonomists. Despite the present decline, traditional taxonomy has been proven to be useful and will be needed for continuous inventorying, including bioprospecting, conservation biology as well as for evolutionary and phylogenic studies (Cotterill and Dangerfield 1997, Baker et al. 1998, Jaspars 1998, Lee 2000). Besides other factors, taxonomists themselves are also responsible for the current decline in the taxonomic studies by not coming up with realistic and clearly achievable goals (Godfray 2002). Taxonomists should come out from their unappealing, non-creative image and should uplift their uniqueness, irreplaceability, importance and necessity in this degrading world. Taxonomy should adopt knowledge from the other disciplines of science, thus reinvent itself to overcome the present crisis, and to cope with the demand of the 21 st century (Godfray 2002).

Finally, concentration should also be given on the development of young botanists, which would involve improving the taxonomy syllabi and teaching techniques in colleges and universities, and also involving them in different programmes on taxonomy, biodiversity and conservation to build up generations that appreciate and care their plant resources. Job opportunities for the taxonomists, which is the main concern of botany students to come into taxonomic research, are there in Bangladesh, especially in this age of ecological sustainability, but we need to upgrade our students' know-how and their outlook to meet the requirements demanded by these professions. 


\section{Acknowledgements}

I would like to thank Prof. A.K.M. Nurul Islam for his support during the preparation and the finalisation of the manuscript. Thanks are also due to the Asiatic Society of Bangladesh and the Bangladesh National Herbarium for allowing me to consult their libraries.

\section{References}

Alam, Sk.S., Nahar, K.K., Sarker, R.H. and Zaman, M.A. 2000. Differential chromosome banding and isozyme analysis of Ampelygonum chinense (L.) Lindley and A. salarkhanii Hassan (Polygonaceae). Bangladesh J. Bot. 29(1): 29-34.

Alberch. P. 1993. Museums, collections and biodiversity inventories. Trends Ecol. Evol. 8(10): $372-$ 375.

Baker, R.H., Yu, X. and DeSalle, R. 1998. Assessing the relative contribution of molecular and morphological characters in simultaneous analysis trees. Molecular Phylogenetics and Evolution 9(3): 427-436.

Beattie, A.J. and Oliver, I. 1994. Taxonomic minimalism. Trends Ecol. Evol. 9(12): 488-490.

Begum, M., Khan, M.S. and Sarkar, A.K. 1994. Cystoliths as a parameter in delimiting taxa of the family Acanthaceae from Bangladesh. Bangladesh J. Plant Taxon. 1(2): 33-46.

Boero, F. 2001. Light after dark: the partnership for enhancing expertise in taxonomy. Trends Ecol. Evol, 16(5): 266.

Bramley, J. 1994. Biodiversity in freshwater ecosystems: the need for an aquatic plant taxonomy course? Freshwater Forum 4(3): 216-218.

Brower, A.V.Z. 1995. Taxonomic minimalism. Trends Ecol. Evol. 10(5): 203.

Cotterill, F.P.D. and Dangerfield, J.M. 1997. The state of biological knowledge. Trends Ecol. Evol. 12(5): 206.

Das, D.K. and Alam, M.K. 2001. Trees of Bangladesh. Government of the People's Republic of Bangladesh, Bangladesh Forest Research Institute, Chittagong, pp. 342.

Disney, H. 1998. Rescue plan needed for taxonomy. Nature 394: 120.

Godfray, H.C.J. 2002. Challenges for taxonomy. Nature 417; 17-19.

Hadiuzzaman, S. 1991. Bryophytes. In: Two Centuries of Plant Studies in Bangladesh and Adjacent Regions (Ed. Islam, A.K.M. Nurul), Asiatic Society of Bangladesh, Dhaka, 155-162.

Hussain, Z. and Acharya, G. (Eds.) 1994. Mangroves of the Sundarbans, Volume Two: Bangladesh. IUCN-The World Conservation Union, Bangkok, Thailand, pp. 257.

Islam, A.K.M. Nurul 1991a. Phycology. In: Two Centuries of Plant Studies in Bangladesh and Adjacent Regions (Ed. Islam, A.K.M. Nurul), Asiatic Society of Bangladesh, Dhaka, 97-153.

Islam, A.K.M. Nurul 1991b. Gymnosperms. In: Two Centuries of Plant Studies in Bangladesh and Adjacent Regions (Ed. Islam, A.K.M. Nurul), Asiatic Society of Bangladesh, Dhaka, 173-174.

Islam, A.K.M. Nurul and Hadiuzzaman, S. 1991. Pteridophytes. In: Two Centuries of Plant Studies in Bangladesh and Adjacent Regions (Ed. Islam, A.K.M. Nurul), Asiatic Society of Bangladesh, Dhaka, 163-171.

Jaspars, M. 1998. Tough time for taxonomy. Nature 394: 413. 
Khan, M.S. 1991. Angiosperms. In: Two Centuries of Plant Studies in Bangladesh and Adjacent Regions (Ed. Islam, A.K.M. Nurul), Asiatic Society of Bangladesh, Dhaka, 175-194.

Khan, M.S. and Halim, M. 1987. Aquatic Angiosperms of Bangladesh. Bangladesh Agricultural Research Council, Dhaka, pp. 120.

Khan, M.S. and Huq, A.M. 1975. Medicinal Plants of Bangladesh: A preliminary list giving actions and uses, Bangladesh Agricultural Research Council, Dacca, pp. 25.

Khan, M.S. et al. (Eds.) 1972-1996. Flora of Bangladesh, No. 1-51. Bangladesh Agricultural Research Council, Dhaka.

Khan, M.S., Rahman, M.M. and Ali, M.A. (Eds.) 2001. Red Data Book of Vascular Plants of Bangladesh. Bangladesh National Herbarium, Dhaka, pp. 179.

Lee, M.S.Y. 2000. A worrying systematic decline. Trends Ecol. Evol. 15(8): 346.

Lhotsky, O. 1998. Species identification as basis for biodiversity evaluation. Verh. Internat. Verein. Limnol. 26: 1741-1742.

Lobo, R.D.B. 1994. Using biodiversity; accomplishments and challenges of the Costa Rican National Biodiversity Institute, INBio. Revista de Biological Tropical 42(1-2): 393-397.

Nishat, A., Huq, S.M.I., Barua, S.P., Reza, A.H.M.A, Khan, A.S.M. (Eds.) 2002. Bio-ecological Zones of Bangladesh. IUCN Bangladesh Country Office, Dhaka, Bangladesh, pp.141.

Renner, S.S. and Ricklefs, R.E. 1994. Systematics and biodiversity. Trend Ecol. Evol. 9(2): 78.

Sobhan, M.I., Alam, Sk.S. and Zaman, M.A. 1991. Cytogenetics of Commelinaceae. XI: Four taxa of Tradescantia. Bangladesh J. Bot. 20(2): 199-206.

Stuessy, T.F. 1990. Plant Taxonomy: the systematic evaluation of comparative data. Columbia University Press, New York, pp. 514.

Valdecasas, A.G., Castroviejo, S. and Marcus, L.F. 2000. Reliance on the citation index undermines the study of biodiversity. Nature 403: 698.

Yoccoz, N.G., Nichols, J.D. and Boulinier, T. 2001. Monitoring of biological diversity in space and time. Trends Ecol. Evol. 16(8): 446-453. 